\title{
A rationale method for evaluating unscrewing torque values of prosthetic screws in dental implants
}

\author{
Felipe Miguel SALIBA ${ }^{1}$, Mayra CARDOSO², Marcelo Ferreira TORRES ${ }^{2}$, Alexandre Carvalho TEIXEIRA², \\ Eduardo José Veras LOURENÇO³, Daniel de Moraes TELLES ${ }^{3}$
}

\author{
1- DDS, MSC, Assistant Professor, Department of Prosthodontics, Dental School, Estácio de Sá University, Rio de Janeiro, RJ, Brazil. \\ 2- DDS, MSC, Department of Prosthodontics, Dental School, State University of Rio de Janeiro, Rio de Janeiro, RJ, Brazil. \\ 3- DDS, MSC, PhD, Associate Professor, Department of Prosthodontics, Dental School, State University of Rio de Janeiro, Rio de Janeiro, RJ, Brazil.
}

Corresponding address: Mayra Cardoso - mayra.cardoso@bol.com.br - Universidade Estadual do Rio de Janeiro - Departamento de Prótese - Avenida Boulevard 28 de Setembro no 157 - Sala 414 - 20551-030 - Rio de Janeiro, RJ - Brasil - Phone: +55 21 2587-6457

Received: May 25, 2009 - Modification: March 25, 2010 - Accepted: September 14, 2010

\section{ABSTRACT}

$\mathrm{O}$ bjectives: Previous studies that evaluated the torque needed for removing dental implant screws have not considered the manner of transfer of the occlusal loads in clinical settings. Instead, the torque used for removal was applied directly to the screw, and most of them omitted the possibility that the hexagon could limit the action of the occlusal load in the loosening of the screws. The present study proposes a method for evaluating the screw removal torque in an anti-rotational device independent way, creating an unscrewing load transfer to the entire assembly, not only to the screw. Material and methods: Twenty hexagonal abutments without the hexagon in their bases were fixed with a screw to 20 dental implants. They were divided into two groups: Group 1 used titanium screws and Group 2 used titanium screws covered with a solid lubricant. A torque of 32 $\mathrm{Ncm}$ was applied to the screw and then a custom-made wrench was used for rotating the abutment counterclockwise, to loosen the screw. A digital torque meter recorded the torque required to loosen the abutment. Results: There was a significant difference between the means of Group $1(38.62 \pm 6.43 \mathrm{Ncm})$ and Group $2(48.47 \pm 5.04 \mathrm{Ncm})$, with $\mathrm{p}=0.001$. Conclusion: This methodology was effective in comparing unscrewing torque values of the implant-abutment junction even with a limited sample size. It confirmed a previously shown significant difference between two types of screws.

Key words: Dental implants. Biomechanics. Torque.

\section{INTRODUCTION}

When joined by a screw, the platform of a dental implant forms with the surface of the base of a prosthetic abutment a connection that should remain stable for the entire life of the restoration. However, loosening of the screws is a matter of concern for both dental professionals and manufacturers, and it is described in the literature as a frequent complication of prostheses placed upon implants ${ }^{3,16}$. The reported rates of loosening vary, going as high as $12.5 \% 6,9,13,14,17$. As the torque applied during the tightening of the screw increases, it generates a larger preload between the base of the component and the platform of the implant. It is intended to reduce the probability of loosening of the screw after the prosthesis is put into use because the larger the preload, the larger the resistance to loosening ${ }^{1}$.

The forces that keep a screw tight are the friction between the threads, between the head of the screw and the abutment, and between the implant and the abutment. The force that clamps two screw-tightened components together is called the "preload" and it depends on the composition of the materials, the texture of their surface and their degree of lubrication ${ }^{2,19}$. The friction coefficient between the contact surfaces is a significant factor and it also affects the preload values ${ }^{10}$.

Aware of the loosening problem, the 
manufacturers of various systems have developed screws designed to decrease the loosening rates. Their surfaces have been treated to reduce the friction coefficient and thus increase the preload. One example is the TorqTite ${ }^{\circledR}$ (Nobel Biocare Holding AG, Balsberg, Kloten, Switzerland), lined with diamond-like carbon (DLC), which acts as a lubricant ${ }^{8,12}$.

The published studies that evaluate the torque needed for removing the screws do not consider the manner of transfer of the occlusal loads to the interfaces between the implant, the abutment and the screw in the clinical setting ${ }^{15,18,20}$. Instead, the torque used for removal is applied directly to the screw. Most of them omit the possibility that the hexagon or any other anti-rotational device could limit the action of the occlusal load in the loosening of the screws. In fact, the concept that attributes to the hexagon the responsibility for preventing loosening of the screw conflicts with the clinical results obtained thus far ${ }^{5}$.

The role of the hexagon in preventing loosening of the screw is controversial ${ }^{7}$. Binon ${ }^{1}$ (1996) assumes that the hexagon significantly increases the resistance to screw loosening, and that the reduction in the rotational discrepancy between the hexagon of the prosthetic abutment and the external hexagon of the implant make the connection more rigid and resistant to loosening. That author believes that a rotational discrepancy greater than 2 degrees in the connection makes it more unstable when subjected to the masticatory load, whereas Lang, Wang and May ${ }^{11}$ (2002) tolerate a discrepancy of up to 5 degrees. On the other hand, Cibirka, et al. ${ }^{4}$ (2001) observed that intentional discrepancies between the hexagons of the implant and the abutment, and even the removal of the hexagon from the implant, did not significantly affect screw loosening. Therefore, evaluation of the resistance to loosening of screws must be independent from the controversial action of anti-rotational devices.

The present study proposes a method for evaluating the torque of screw removal, and has two distinct objectives: (1) to isolate the behavior of the screw from that of the anti-rotational device; and (2) to create an unscrewing load transfer, not only to the screw, but to the entire assembly, similar to what occurs in the mouth.

\section{MATERIAL AND METHODS}

We used 20 dental implants made of commercially pure titanium (Neodent Implantes Osteointegráveis, Curitiba, Paraná, Brazil), $3.75 \times 9.0 \mathrm{~mm}$, with a platform of $4.1 \mathrm{~mm}$ in diameter, and an external hexagon $2.7 \mathrm{~mm}$ wide and $0.7 \mathrm{~mm}$ high (similar to the original Brånemark platform). For this

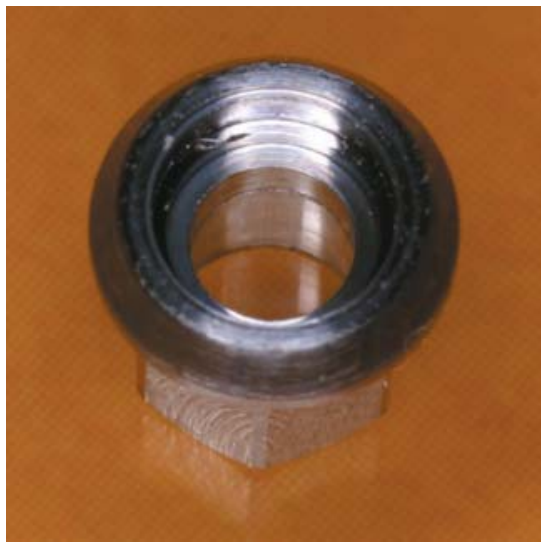

Figure 1- Inner view of the hexagonal abutment after removal of the hexagon

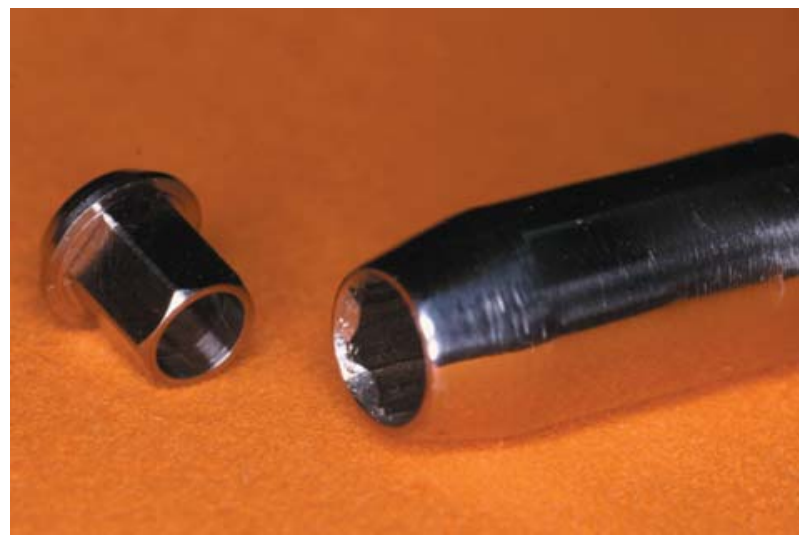

Figure 2- One of the ends of the custom-made wrench that fits onto the hexagonal abutment for loosening the screw

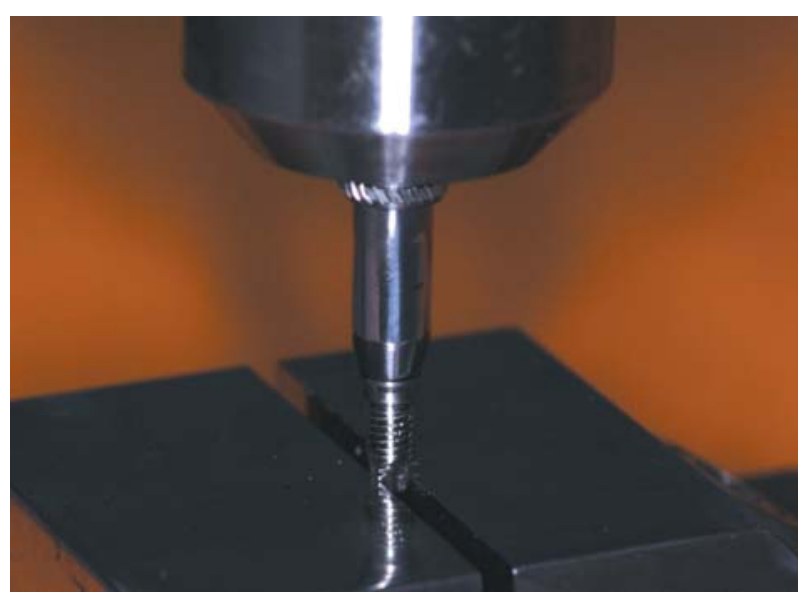

Figure 3- The wrench attached to the digital torque meter turning the hexagonal abutment counterclockwise. The abutment is held by a metal base

study, 20 hexagonal abutments (Neodent) were manufactured without a hexagon in their bases so they could be rotated on the implant platform during the loosening of the fixation screw (Figure 1). These abutments are recommended for cemented single crowns. A wrench custom made for this experiment (Neodent) was used for rotating the hexagonal 


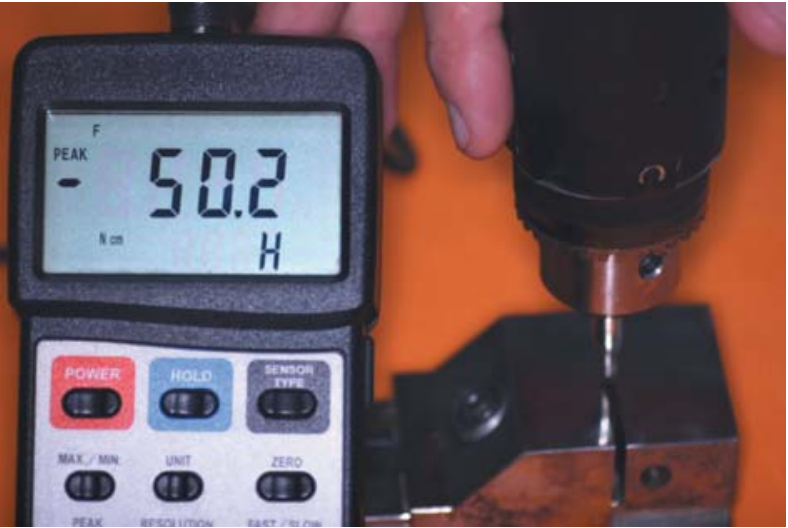

Figure 4- The digital torque meter showing the maximum torque required for loosening the screw

abutment counterclockwise, thus creating a movement to loosen the screw (Figure 2).

The implant-hexagonal abutment assemblies were randomly divided into two groups of ten each. In Group 1, each abutment was fixed to an implant with an M2.0 titanium screw (Neodent), while in Group 2 titanium screws M2.0 covered with a solid lubricant (TorqTite ${ }^{\circledR}$, Nobel Biocare) were used. For fixation of the abutment, the implants were attached to metal base that kept them from rotating when tightening torque was being applied to the screw. The abutment was attached with a screw, first using a hexagonal $1.2 \mathrm{~mm}$ digital wrench (Neodent), followed by tightening with a prosthetic ratchet torque wrench (Neodent) up to a torque of $32 \mathrm{Ncm}$. A digital torque meter (TQ680 , Instrutherm, São Paulo, SP, Brazil) was then employed for verification of the torque applied to the screw.

After confirmation of the torque, this same torque meter was used for applying a removal movement to the abutment. One end of the custom-made wrench was attached to the digital torque meter

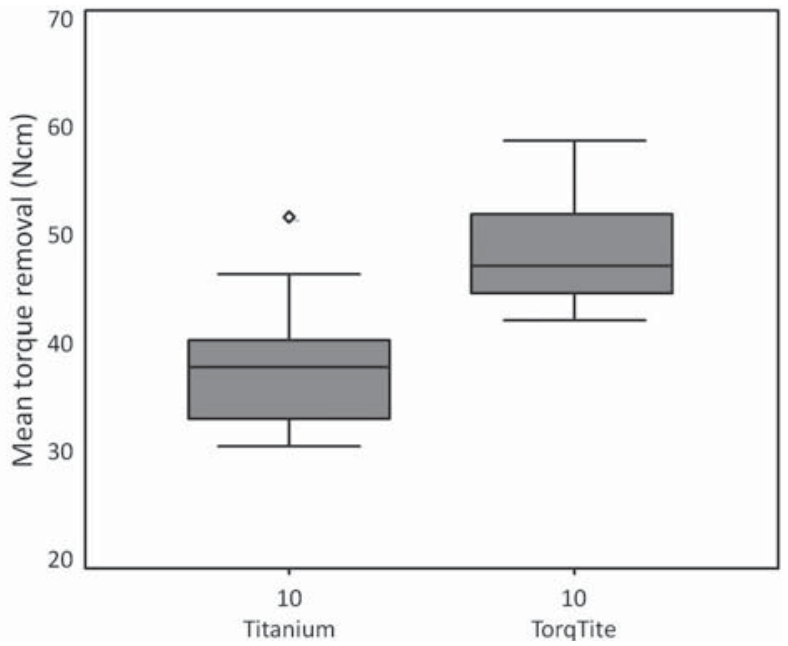

Figure 5- Torque values ( $\mathrm{Ncm}$ ) for removing the abutments from the plain titanium screws (Neodent, Brazil) and from the titanium screws covered with lubricant (TorqTite $\AA$, Nobel Biocare, Switzerland)

and the other end was attached to the abutment. Then, counterclockwise torque was applied and the highest torque required to completely loosen the abutment was recorded (Figures 3 and 4). It should be mentioned that the loosening of the abutment occurred only because the hexagon at its base had been removed, thus eliminating the possibility of any effect of the hexagon upon the experiment. Each experiment was performed four times for each implant-abutment-screw assembly. The values obtained for each group were statistically compared with the two-sample Student's t-test at the significance level of $5 \%$.

\section{RESULTS}

The results are presented in Tables 1 and 2, and in Figure 5. The normality of the samples was

Table 1- Torque values for removing the abutments from the plain titanium screws (Neodent, Brazil)

\begin{tabular}{cccccc}
\hline Sample & \multicolumn{4}{c}{ Removal Torque $(\mathbf{N c m})$} & \multicolumn{2}{c}{ Mean torque (Ncm) } \\
\hline & Test 1 & Test 2 & Test 3 & Test 4 & \\
1 & 29.1 & 36.5 & 38.2 & 38.7 & 35.63 \\
2 & 39.5 & 38.0 & 38.6 & 43.3 & 39.85 \\
3 & 42.1 & 46.0 & 41.8 & 55.5 & 46.35 \\
4 & 49.8 & 38.4 & 36.3 & 37.3 & 40.45 \\
5 & 33.3 & 38.6 & 35.6 & 36.3 & 35.95 \\
6 & 29.0 & 26.2 & 37.3 & 31.5 & 31.0 \\
7 & 34.4 & 34.9 & 32.7 & 32.1 & 33.53 \\
8 & 23.0 & 28.7 & 35.5 & 41.1 & 32.08 \\
9 & 58.4 & 53.8 & 50.3 & 43.0 & 51.38 \\
10 & 49.4 & 34.4 & 39.5 & 36.6 & 39.98 \\
\hline
\end{tabular}


Table 2- Torque values for removing the abutments from the titanium screws covered with lubricant (TorqTite $₫$, Nobel Biocare, Sweden)

\begin{tabular}{cccccc}
\hline Sample & & \multicolumn{2}{l}{ Removal Torque $(\mathbf{N c m})$} & Mean torque (Ncm) \\
\hline & Test 1 & Test 2 & Test 3 & Test 4 & 58.38 \\
\hline 2 & 53.1 & 56.5 & 59.3 & 64.6 & 49.83 \\
3 & 41.3 & 50.9 & 49.7 & 57.4 & 47.13 \\
4 & 27.3 & 39.5 & 59.9 & 61.8 & 47.23 \\
5 & 39.7 & 46.3 & 49.8 & 53.1 & 43.43 \\
6 & 30.8 & 45.0 & 46.3 & 51.6 & 53.93 \\
7 & 37.7 & 44.8 & 54.5 & 78.7 & 46.28 \\
8 & 26.6 & 52.2 & 56.9 & 49.9 & 51.73 \\
\hline 9 & 58.1 & 46.3 & 48.7 & 53.8 & 44.50 \\
\hline
\end{tabular}

confirmed by the Kolmogorov-Smirnov and ShapiroWilk tests. The t-test showed a significant difference between the means of Group 1 (titanium screws; $38.62 \mathrm{Ncm} \pm 6.43$ ) and Group 2 (TorqTite screws; $48.47 \mathrm{Ncm} \pm 5.04)$, with $p=0.001$.

\section{DISCUSSION}

The methodology used in this study produced results similar to those reported by Lang, et al.10 (2003) and Martin, et al. ${ }^{12}$ (2001), namely, it confirmed that titanium screws with a surface covered with solid lubricants perform better than plain titanium screws in terms of preserving the stability of the prosthetic implant-abutment junction. The standard deviation found in this study was smaller than that found by Martin, et al. ${ }^{12}$ (2001), while both used the same number of screws. This shows better homogeneity in the measurements and suggests a higher precision in the presented methodology.

In the methods usually employed for measuring the unscrewing torque, the latter is applied directly to the screw, which is not realistic considering that clinically the screw loosening occurs as a result of small movements of the abutment. Therefore, the methods that loosen the screws directly do not reproduce accurately what happens to the prostheses in the mouth of the patients. The method proposed in this study is more appropriate because: (1) it permits evaluating the performance of screws independently from anti-rotational devices; and (2) it produces results closer to the clinical situation because the unscrewing force is applied upon the prosthetic assembly instead of directly on the screw.

The results showed that unscrewing torque was higher than screwing torque applied. This can possibly be due to the fact that the force needed to rotate the abutment had to overcome the friction between the surfaces of the abutment and the implant, besides the friction on the surface of the screw.

The results also showed a homogeneous sample despite the small number of screws. The hexagons were removed from the abutments to eliminate their possible role in influencing the preload, rather than because of any notion that they are not useful, and also to make possible to rotate the abutment until the loose of preload. Although this type of abutment does not exist without the hexagon in clinical reality, there are many types of abutments with no kinds of anti-rotational devices at all, similar to the experimental abutments used in this study, and they are largely used in clinical situation.

The proposed method may permit the evaluation of clinically significant issues, such as the influence of the number of screwing and unscrewing events upon the preload. Furthermore, this method may be enhanced by applying cyclical loads to the abutment so that the direction of the loads can be varied within the same cycle in order to create small motions even more similar to the clinical reality.

\section{CONCLUSION}

Within the limitations of this in vitro study, the following conclusion may be drawn: 1 . The proposed method is effective in comparing unscrewing torque values of the implant-abutment junction even with a limited sample size. 2. This method confirmed a previously shown significant difference between two types of screws. 


\section{REFERENCES}

1- Binon PP. The effect of implant/abutment hexagonal misfit on screw joint stability. Int J Prosthodont. 1996;9:149-60.

2- Burguete RL, Johns RB, King T, Patterson EA. Tightening characteristics for screwed joints in osseointegrated dental implants. J Prosthet Dent. 1994;71:592-9.

3- Carlson B, Carlsson GE. Prosthodontic complications in osseointegrated dental implant treatment. Int J Oral Maxillofac Implants. 1994;9:90-4.

4- Cibirka RM, Nelson SK, Lang BR, Rueggeberg FA. Examination of the implant-abutment interface after fatigue testing. J Prosthet Dent. 2001;8:268-75.

5- Ekfeldt A, Carlsson GE, Börjesson G. Clinical evaluation of single-tooth restorations supported by osseointegrated implants: a retrospective study. Int J Oral Maxillofac Implants. 1994;9:179-83. 6- Jung RE, Pjetursson BE, Glauser R, Zembic A, Zwahlen M, Lang NP. A systematic review of the 5-year survival and complication rates of implant-supported single crowns. Clin Oral Implants Res. 2008; 19:119-30.

7- Khraisat A, Hashimoto A, Nomura S, Miyakawa O. Effect of lateral cyclic loading on abutment screw loosening of an external hexagon implant system. J Prosthet Dent. 2004;91:326-34.

8- Kim SK, Lee JB, Koak JY, Heo SJ, Lee KR, Cho LR, et al. An abutment screw loosening study of a Diamond Like Carbon-coated CP titanium implant. J Oral Rehabil. 2005;32:346-50.

9- KreissI ME, Gerds T, Muche R, Heydecke G, Strub JR. Technical complications of implant-supported fixed partial dentures in partially edentulous cases after an average observation period of 5 years. Clin Oral Implants Res. 2007;18:720-6.

10- Lang LA, Kang B, Wang RF, Lang BR. Finite element analysis to determine implant preload. J Prosthet Dent. 2003;90:539-46.
11- Lang LA, Wang RF, May KB. The influence of abutment screw tightening on screw joint configuration. J Prosthet Dent. 2002;87:74-9.

12- Martin WC, Woody RD, Miller BH, Miller AW. Implant abutment screw rotations and preloads for four different screw materials and surfaces. J Prosthet Dent. 2001;86:24-32.

13- Pjetursson BE, Tan K, Lang NP, Brägger U, Egger M, Zwahlen M. A systematic review of the survival and complication rates of fixed partial dentures (FPDs) after an observation period of at least 5 years. Clin Oral Implants Res. 2004;15:625-42.

14- Sailer I, Philipp A, Zembic A, Pjetursson BE, Hämmerle $\mathrm{CH}$, Zwahlen M. A systematic review of the performance of ceramic and metal implant abutments supporting fixed implant reconstructions. Clin Oral Implants Res. 2009;20(sp. Issue):4-31.

15- Stüker RA, Teixeira ER, Beck JCP, Costa NP. Preload and torque removal evaluation of three different abutment screws for single standing implant restorations. J Appl Oral Sci. 2008;16:55-8.

16- Taylor TD. Prosthodontic problems and limitations associated with osseointegration. J Prosthet Dent. 1998;79:74-8.

17- Theoharidou A, Petridis HP, Tzannas K, Garefis P. Abutment screw loosening in single-implant restorations: a systematic review. Int J Oral Maxillofac Implants. 2008;23:681-90.

18- Tzenakis GK, Nagy WW, Fournelle RA, Dhuru VB. The effect of repeated torque and salivary contamination on the preload of slotted gold implant prosthetic screws. J Prosthet Dent. 2002;88:183-91.

19- Wang RF, Kang B, Lang LA, Razzoog ME. The dynamic natures of implant loading. J Prosthet Dent. 2009;101:359-71.

20- Weiss EI, Kozak D, Gross MD. Effect of repeated closures on opening torque values in seven abutment-implant systems. J Prosthet Dent. 2000;84:194-9. 